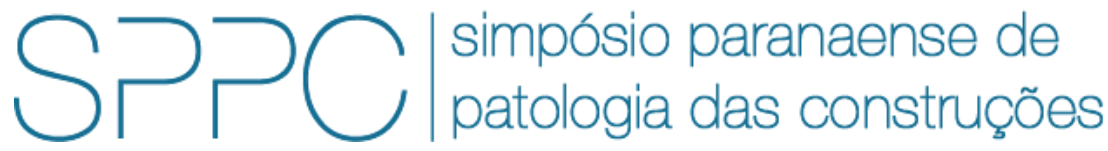

ISSN 2526-7248 artigo 2SPPC1001, pp. 1-13, 2017

\title{
Argamassas de reparo estrutural: Resistência de aderência sob diferentes formas de solicitação
}

\author{
Vitor Lorival Kudlanvec Junior ${ }^{1,2,3}$, Marienne do Rocio de Mello Maron da Costa ${ }^{4}$ \\ ${ }^{1}$ Mestrando, Universidade Federal do Paraná, vitorlorival86@ufpr.br \\ 2 Professor, Faculdade Educacional de Araucária \\ ${ }^{3}$ Engenheiro Civil, AS Estruturas Engenheiros Associados SS Ltda. \\ ${ }_{4}^{4}$ Professora Doutora, Universidade Federal do Paraná, mariennemaron@gmail.com
}

Resumo: Um sistema adequado de reparo de estruturas de concreto deve apresentar certos requisitos de compatibilidade com a estrutura original no que diz respeito às deformações. Um ponto de fundamental importância no sistema de reparo compatibilizado é a troca de tensões entre matriz e substrato, dada através da aderência entre estes dois meios. A resistência de aderência, fornecida pela matriz através de ligações físicas e químicas é um processo complexo devido à não linearidade de comportamento de elementos cimentíceos. Este estudo tem por objetivo avaliar a resistência de aderência de cinco argamassas industrializadas comercializadas em Curitiba/PR quanto ao seu comportamento sob ação de quatro esforços de natureza diferentes: tração direta, tração na flexão, cisalhamento direto e cisalhamento oblíquo. Para tal, foram utilizados ensaios que simulam o efeito destes esforços adaptando geometricamente os corpos de prova e o plano de aplicação das cargas. Os resultados, comprovados estatisticamente por teste de variância, mostram que o comportamento da aderência das argamassas quando solicitadas por diferentes esforços é significativamente diferente, sendo que as tensões resistentes são beneficiadas quando há plano de compressão sobre a zona de transição. A resistência de aderência ao cisalhamento direto mostrou-se superior à do próprio substrato em quatro argamassas testadas.

Palavras-chave: argamassas de reparo, reparo estrutural, aderência, patologia das construções.

Abstract: An appropriate concrete structure repair system must have compatibility requirements with the original structure in respect to deformations. A point of fundamental importance in the compatibilized repair system is the exchange of tensions between matrix and substrate, given through the adhesion between these two media. The adhesion resistance provided by the matrix through physical and chemical bonding is a complex process due to nonlinear behavior of cementitious elements. The objective of this study was to evaluate the adhesion strength of five industrialized mortars commercialized in Curitiba/PR, under the influence of four different stresses: direct tensile, flexural tensile, direct shear and oblique shear. For that, we used tests that simulate the effect of these efforts by geometrically adapting the specimens and the directions of the loadings. The results have been statistically proved through an ANOVA test and showed that the adhesion behavior of the mortars when requested by different loadings are significantly different, and the tensile strengths are benefited when there is a compression plane over the transition zone. The direct shear adhesion strength was superior to that of the substrate in four mortars tested.

Keywords: repair mortars, structural repair, adherence, pathology of building constructions. 
KUDLANVEC JUNIOR, V.L.; COSTA, M.R.M.M, ARGAMASSAS DE REPARO ESTRUTURAL: RESISTÊNCIA DE ADERÊNCIA SOB DIFERENTES FORMAS DE SOLICITAÇÃO. $2^{\circ}$ Simpósio Paranaense de Patologia das Construções (2० SPPC), artigo 2SPPC1001, pp. 1-13, 2017. DOI: 10.4322/2SPPC.2017.001

\section{Introdução}

Dentro da escolha de uma argamassa de reparo existem requisitos de desempenho que devem ser obedecidos ou pelo menos considerados, tais como: compatibilidade, retração, função, tecnologia e durabilidade [1]. Dentre estes requisitos, a compatibilidade é o que determina o funcionamento adequado entre o reparo e a superfície a ser reparada, e que o material de reparo introduzido não vai trazer consequências negativas à construção original no futuro [2]. A principal razão para o não sucesso de reparos estruturais duráveis é o foco exclusivamente na própria fase de reparo, ignorando a consequência deste procedimento sobre o desempenho global da estrutura, quebrando a compatibilidade do sistema [3].

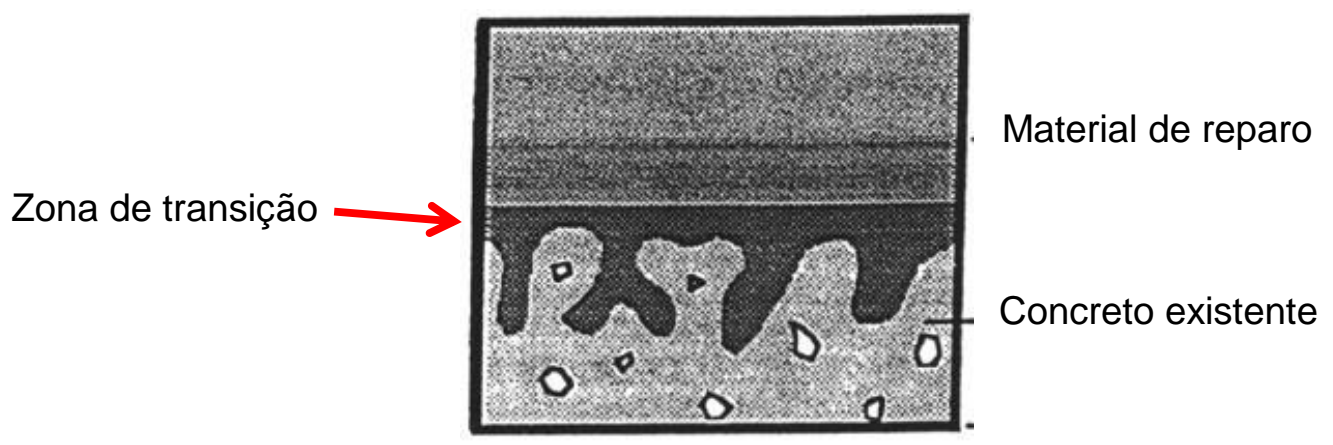

Figura 1: Modelo de um sistema de reparo em estrutura de concreto [3].

Para Schueremans et al. [1] é importante levar em conta a caracterização química, estética, física e mecânica para avaliar o desempenho global do reparo. A compatibilidade só pode ser alcançada seguindo uma abordagem multidisciplinar, onde todas as partes envolvidas no projeto possam avaliar os requisitos de desempenho a serem apresentadas para a argamassa de reparo e então seja definido o material para este fim.

Aderência é um dos fatores de compatibilidade a serem estudados para um reparo ter sucesso, e, para se avaliar aderência entre reparo e substrato, deve-se levar em conta os seguintes fatores: simulação de local, exposição às condições ambientais, indução a esforços típicos da estrutura em serviço, avaliação da validade dos resultados para a estrutura real, sensibilidade para analise das variações de resultados e possibilidade de reprodução em estruturas reais [4].

A formação de aderência de uma matriz de reparo em um substrato de concreto é dada através das ligações mecânicas e químicas formadas durante o processo de hidratação dos aglomerantes desta matriz [5]. Este processo, que caracteriza a zona de transição do sistema de reparo, é complexo devido à não linearidade de comportamento físico de materiais cimentíceos e estudá-lo de forma adequada é de fundamental importância para o entendimento do assunto.

O propósito deste estudo é avaliar o comportamento das argamassas de reparo em contato com o substrato de concreto sob diferentes formas de solicitação: tração direta, tração na flexão, cisalhamento direto e cisalhamento oblíquo, esforços que são usuais durante a vida útil de uma estrutura civil e discutir sobre a variabilidade destes resultados dentro de cada ensaio. 
KUDLANVEC JUNIOR, V.L.; COSTA, M.R.M.M, ARGAMASSAS DE REPARO ESTRUTURAL: RESISTÊNCIA DE ADERÊNCIA SOB DIFERENTES FORMAS DE SOLICITAÇÃO. $2^{\circ}$ Simpósio Paranaense de Patologia das Construções (2० SPPC), artigo 2SPPC1001, pp. 1-13, 2017. DOI: 10.4322/2SPPC.2017.001

\section{Materiais e métodos}

\subsection{Materiais}

O estudo fez uso de cinco (5) tipos de argamassas de reparo industrializadas disponíveis no mercado da construção civil de Curitiba/PR. Estes produtos foram escolhidos como sendo os mais vendidos e que possuem indicação de uso semelhantes entre si - aplicação em obras de concreto armado comuns para reparo de manifestações patológicas localizadas. As características de estados fresco e endurecido das argamassas estão apresentadas na tabela 1 e foram obtidas através de ensaios normatizados pela NBR 13278 [6] (densidade e teor de ar incorporado) e pela NBR 13279 [7] (resistências mecânicas). A relação de mistura líquido/pó é fornecida pelos respectivos fabricantes.

Tabela 1: Propriedades de estado fresco e endurecido das argamassas utilizadas.

\begin{tabular}{|c|c|c|c|c|c|c|c|c|c|}
\hline \multirow[t]{2}{*}{$\begin{array}{l}\text { Argamas- } \\
\text { sa }\end{array}$} & \multirow[t]{2}{*}{$\begin{array}{l}\text { Relação } \\
\text { líquido/pó }\end{array}$} & \multirow{2}{*}{$\begin{array}{l}\text { Dens. } \\
\text { est. } \\
\text { fresco } \\
\left(\mathrm{g} / \mathrm{cm}^{3}\right)\end{array}$} & \multirow[t]{2}{*}{$\begin{array}{c}\text { Ar } \\
\text { incorporado } \\
(\%)\end{array}$} & \multicolumn{3}{|c|}{$\begin{array}{l}\text { Resistência à } \\
\text { tração (MPa) }\end{array}$} & \multicolumn{3}{|c|}{$\begin{array}{c}\text { Resistência à } \\
\text { compressão } \\
\text { (MPa) }\end{array}$} \\
\hline & & & & 1 & 7 & 28 & 1 & 7 & 28 \\
\hline $\mathrm{Al}-1$ & 0,1450 & 2,19 & 1,2 & 5,6 & 11,1 & 12,5 & 31,6 & 51,5 & 60,7 \\
\hline Al-2 & 0,1625 & 2,14 & 1,1 & 5,0 & 8,5 & 9,7 & 23,7 & 52,1 & 56,6 \\
\hline Al-3 & 0,1248 & 1,94 & 10,8 & 2,6 & 3,8 & 2,8 & 9,9 & 11,7 & 14,6 \\
\hline $\mathrm{Al}-4$ & 0,1300 & 2,08 & 8,2 & 1,4 & 6,7 & 8,5 & 4,0 & 38,3 & 42,1 \\
\hline Al-5 & 0,1470 & 1,92 & 14,7 & - & 7,0 & 7,8 & - & 27,1 & 30,2 \\
\hline
\end{tabular}

\subsection{Metodologia}

A avaliação dos esforços de resistência de aderência com o substrato de concreto foram avaliados através de quatro ensaios distintos, sendo que dois deles avaliam a tensão normal limite de aderência - tração direta e tração na flexão - e dois deles a tensão tangencial - cisalhamento direto e obliquo.

A moldagem dos corpos de prova depende da modalidade do ensaio e são descritas individualmente. Estes, após moldados, permaneceram em processo de cura ao ar livre com temperatura e umidade controladas em câmara seca, de $20^{\circ} \mathrm{C}$ e $60 \%$ respectivamente, a fim de criar padronização de perda de umidade entre todas as amostras.

O preparo do substrato foi feito com base em manuais de procedimentos de reparo estrutural [8], [9] no que diz respeito à superfície ideal. Foi utilizado concreto de resistência característica $f_{c k}=25 \mathrm{MPa}$, com traço em massa $1: 2,17: 2,94$, relação água/cimento de 0,60 e teor de argamassa de 51\%. O cimento utilizado para sua confecção foi do tipo CPII-F 32, agregado miúdo de origem natural e agregado graúdo em forma de pedrisco, que, devido às dificuldades de moldagem de corpos de prova pequenos com agregados de maior diâmetro, permite uma concessão ao uso de formas prismáticas de 40×40×160 milímetros e de placas com 20 milímetros de espessura.

O controle de umidade da superfície do substrato foi feito através de borrifos de água, mantendo a superfície úmida e sem acúmulo de água, evitando assim a fragilização 
da zona de interface do sistema por aumento significativo da relação água/cimento localizada [10].

\subsubsection{Resistência de aderência à tração direta}

O ensaio de resistência de aderência à tração direta foi baseado no método descrito pela NBR 13528 [11], porém com modificações que se adaptem à argamassas de reparo. Foram ensaiados quatro (4) corpos de prova para a idade de 28 dias de hidratação, moldados sobre substrato de concreto conforme figura 2 e rompidos através do equipamento Pull-off Tester Dyna Z16E da marca Proceq, operado manualmente com taxa de carga definida de $50 \mathrm{~N} / \mathrm{s}$. A velocidade é controlada pelo visor de um dinamômetro acoplado ao Pull-off que permite visualizar a força aplicada no corpo de prova (fig. 3). O Pull-off Tester é ligado à pastilha, presa ao corpo de prova com adesivo epóxi de alta resistência, através de pino em encaixe rotulado, evitando a transferência de esforços secundários. A superfície do substrato foi preparada com escarificação nos locais de moldagem dos corpos de prova e posterior limpeza.

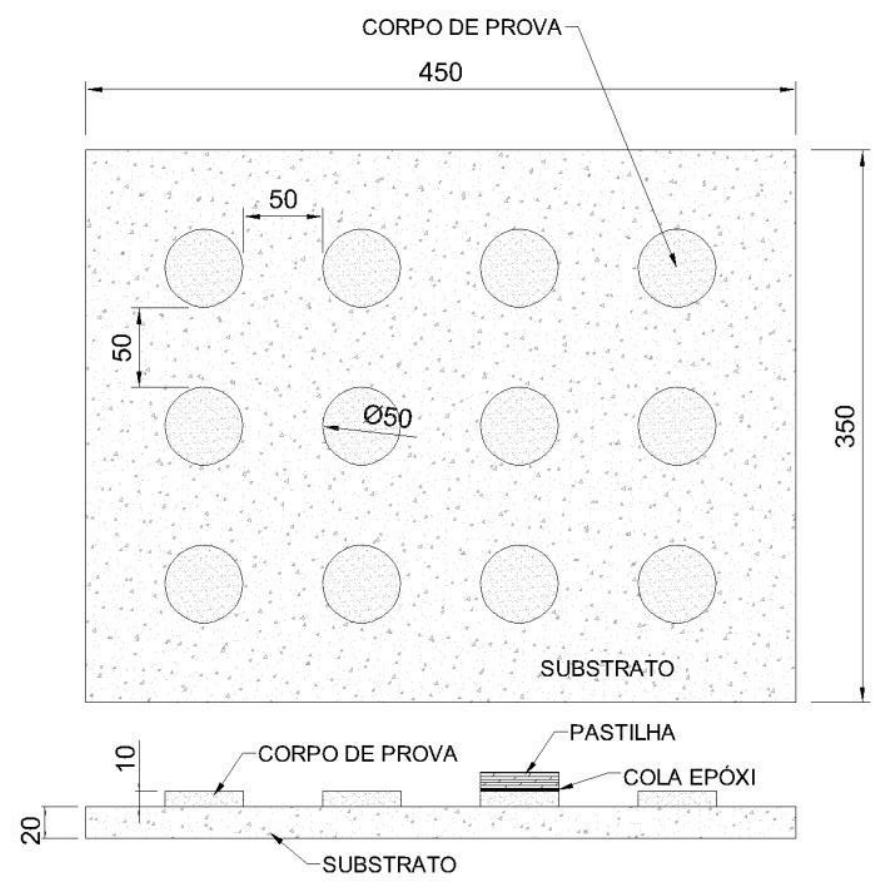

Figura 2: Disposição dos corpos de prova sobre o substrato de concreto. 


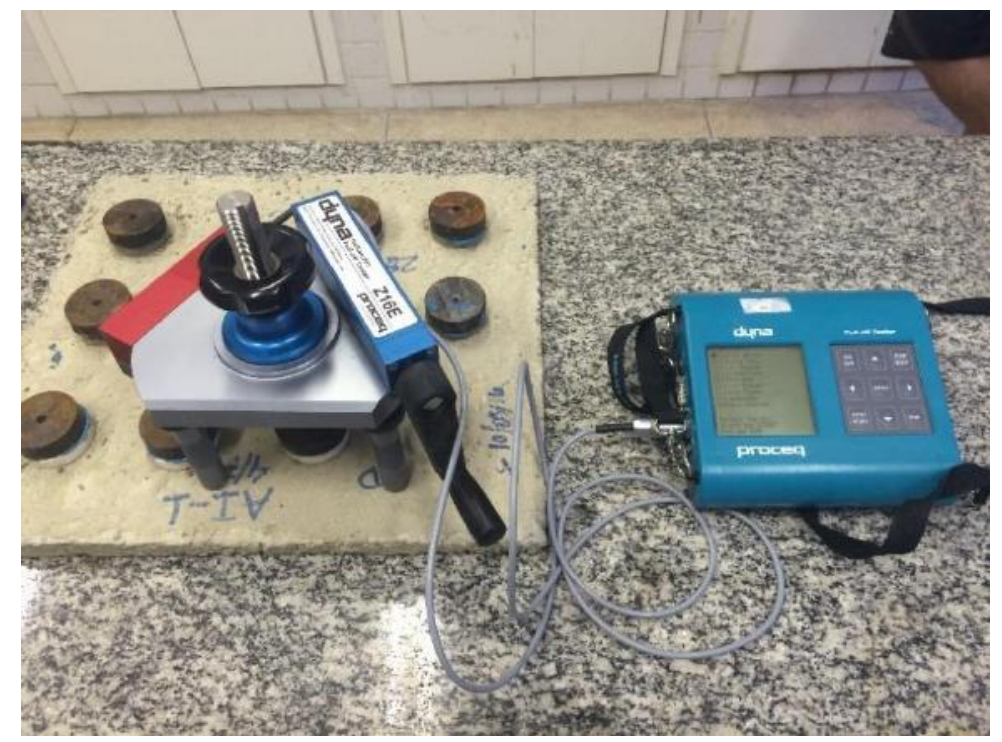

Figura 3: Pull off tester e dinamômetro para ensaio de resistência à tração direta.

\subsubsection{Resistência de aderência à tração na flexão}

O método de ensaio para determinação da resistência de aderência à tração na flexão foi baseado nos trabalhos [12] e [13]. Este ensaio consiste na montagem e ruptura à flexão de corpos de prova prismáticos de $40 \times 40 \times 160$ milímetros, sendo 80 milímetros da sua extensão preenchido de concreto (substrato) e os outros 80 milímetros com argamassa de reparo, conforme figura 4. A moldagem do substrato foi realizada em um corpo de prova prismático inteiro, sendo este então rompido à flexão na idade de 7 dias após ser riscado com esmeril no seu comprimento médio (80 milímetros) a fim de concentrar as tensões e evitar ruptura em plano indesejado.

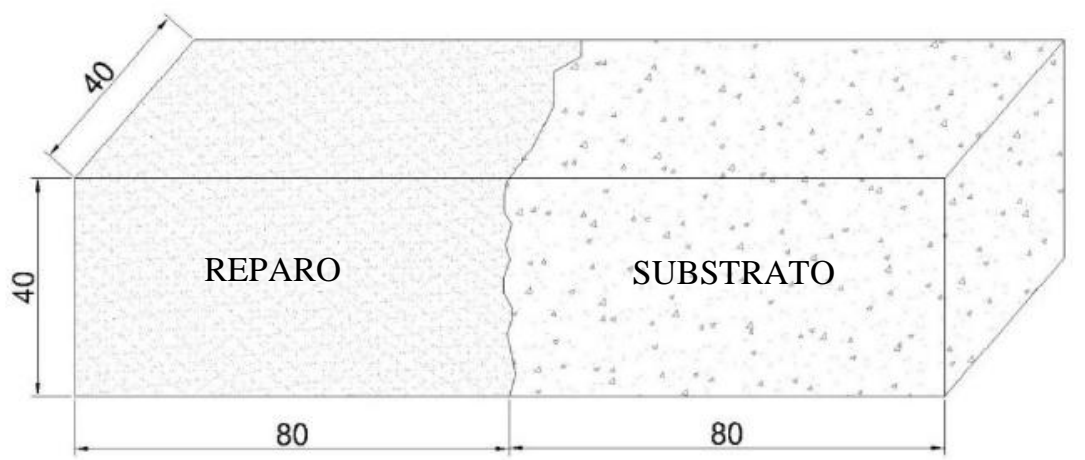

Figura 4: Corpo de prova para ensaio de resistência de aderência à tração na flexão.

Após o tempo de hidratação, a ruptura acontece de forma análoga à estabelecida pela norma NBR 13279 [7], com o plano de aplicação de carga localizado exatamente na interface, conforme mostra a figura 5 , sendo a carga aplicada a uma velocidade de $50 \mathrm{~N} / \mathrm{s}$. 


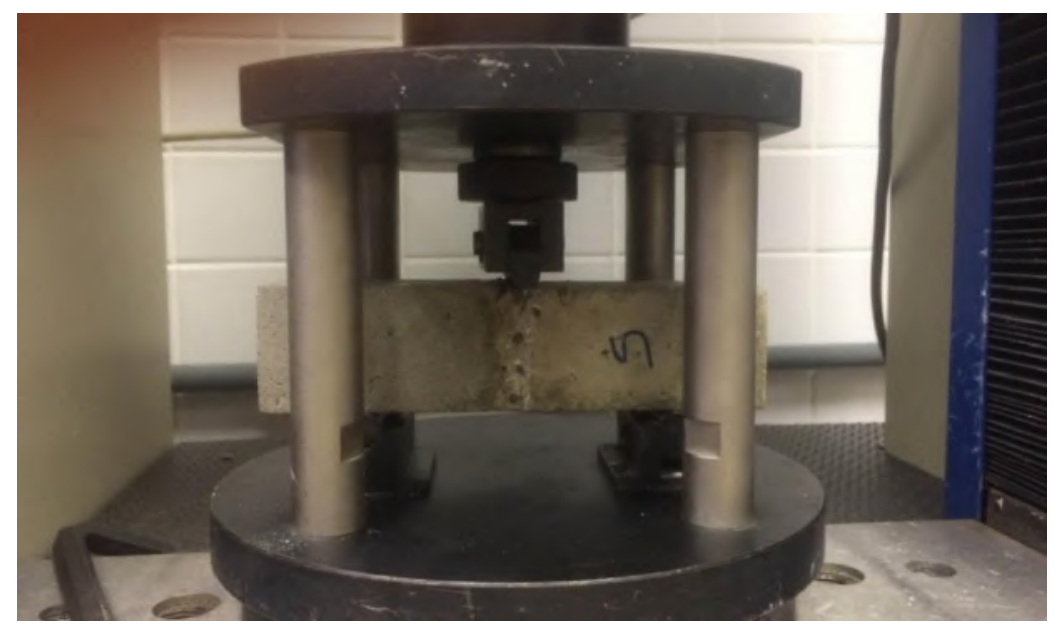

Figura 5: Corpo de prova para ensaio de resistência de aderência à tração na flexão posicionado na prensa.

\subsubsection{Resistência de aderência ao cisalhamento direto}

O ensaio de resistência de aderência ao cisalhamento direto consiste em aplicar carga no sentido transversal ao eixo longitudinal do corpo de prova de $40 \times 40 \times 160$ milímetros, o mesmo utilizado no ensaio de resistência de aderência à tração na flexão e sua metodologia foi baseada em [14]. O corpo de prova é adaptado a um suporte metálico que permite o engastamento do elemento, impedindo qualquer movimentação.

O processo de moldagem, adensamento e cura foi o mesmo aplicado no ensaio de resistência de aderência à tração na flexão descrito em 2.2.2. A carga é aplicada pela prensa a uma velocidade de $50 \mathrm{~N} / \mathrm{s}$ na matriz, em um plano imediatamente adjacente ao plano da interface, conforme mostra a figura 6.

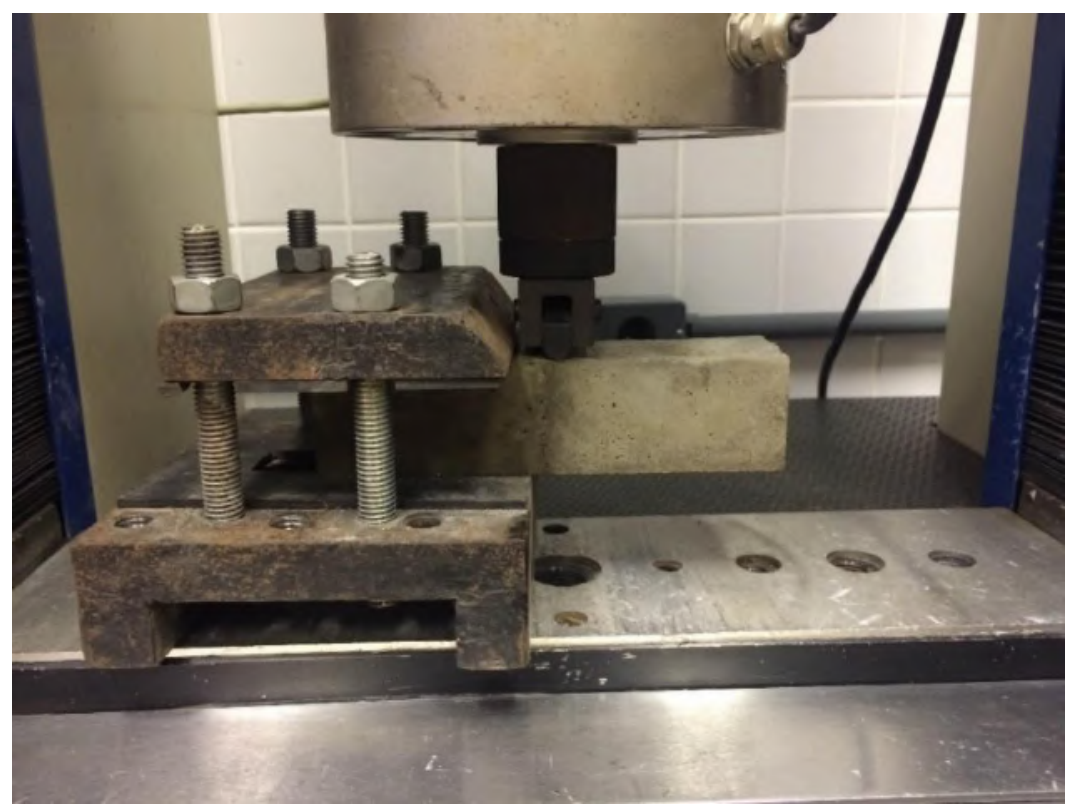

Figura 6: Corpo de prova para ensaio de resistência de aderência ao cisalhamento direto posicionado na prensa. 


\subsubsection{Resistência de aderência ao cisalhamento oblíquo}

A avaliação do cisalhamento oblíquo seguiu a metodologia proposta por [15] e consiste na aplicação de uma carga de compressão no sentido longitudinal de corpo de prova prismático de $40 \times 40 \times 160$ milímetros, composto por substrato e argamassa de reparo separados por um plano de cisalhamento orientado a 30 graus em relação à aresta longitudinal, conforme figuras 7 e 8.
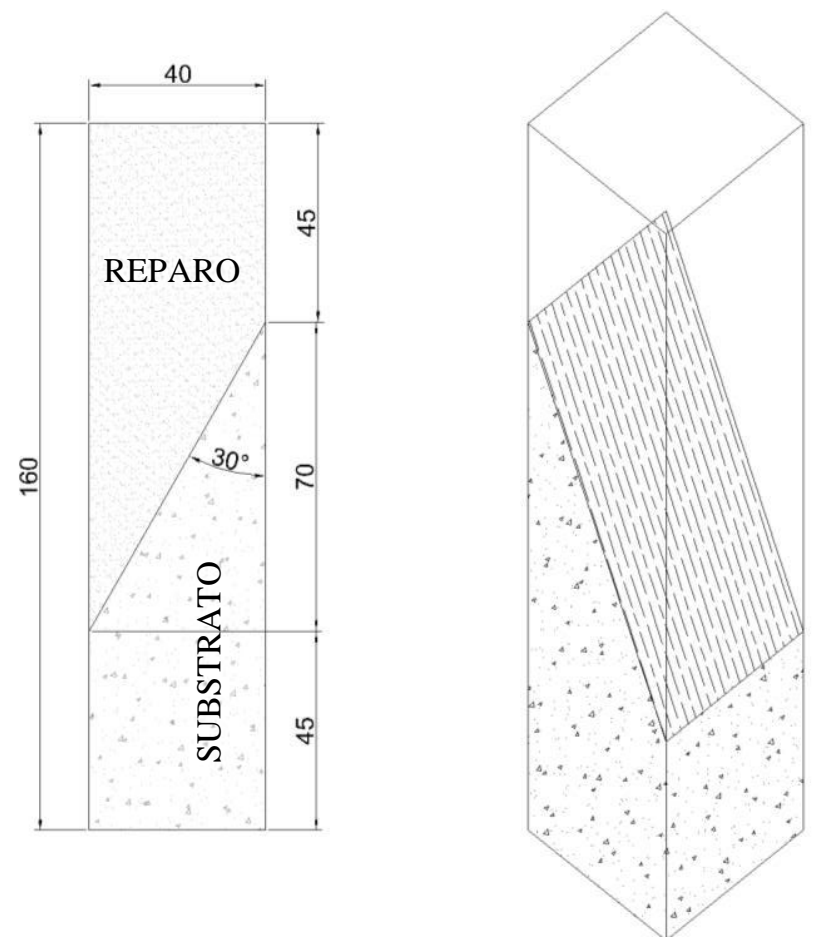

Figura 7: Modelo esquemático do corpo de prova para ensaio de cisalhamento oblíquo.

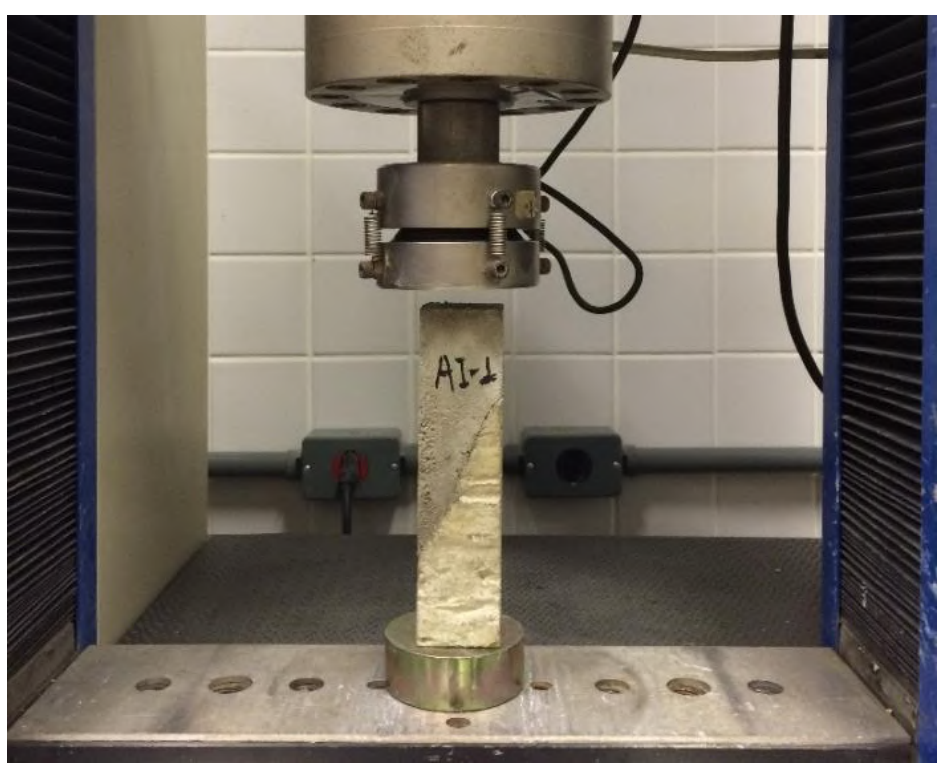

Figura 8: Corpo de prova para ensaio de resistência de aderência ao cisalhamento oblíquo posicionado na prensa. 


\subsection{Modelos matemáticos}

A partir dos resultados obtidos de força limite de ruptura para cada ensaio, deve-se, para equacionar e comparar os resultados, transformá-los em valores de tensão. Para tal, os modelos matemáticos para determinação da tensão limite são baseados no princípio básico da resistência dos materiais (eq. 1 e 2), onde:

$$
\begin{aligned}
\sigma & =\frac{N}{A} \\
\tau & =\frac{Q}{A}
\end{aligned}
$$

Aplicando as condições de contorno nas equações 1 e 2, e convertendo valores de área (para tração direta e cisalhamento direto), momento de inércia e momento solicitante (para tração na flexão) e decompondo os valores de força e área para cisalhamento oblíquo, tem-se a tabela 2 com as equações 3, 4, 5 e 6 determinadas para cálculo das tensões limite de aderência.

Tabela 2: Tensões limite de aderência para cada ensaio deste estudo.

\begin{tabular}{lcc}
\hline \multicolumn{1}{c}{ Ensaio } & Equação da tensão (MPa) & \\
\hline Tração direta & $\sigma=\frac{N}{18}$ & $(3)$ \\
\hline Tração na flexão & $\sigma=\frac{N}{427}$ \\
\hline Cisalhamento direto & $\tau=\frac{Q}{1600}$ \\
\hline Cisalhamento oblíquo & $\tau=\frac{Q}{3.695}$
\end{tabular}

\section{Resultados e discussão}

Os ensaios realizados para a elaboração deste trabalho promoveram os seguintes resultados, apresentados na tabela 3 e na figura 9.

Percebe-se com base nos resultados a diferença entre tensões de resistência de aderência, tanto entre os ensaios quanto entre as argamassas. A Al-3 obteve desempenho bastante inferior às demais amostras ensaiadas, enquanto as argamassas Al-4 e Al-5 tiveram resultados entre a média e Al-1 e Al-2 ficaram na faixa superior.

Há um claro padrão entre os resultados no que envolve o comportamento aos diferentes ensaios. A zona de transição dos sistemas têm melhor desempenho ao cisalhamento oblíquo e tração na flexão, que são esforços cuja geometria de aplicação gera influência de zonas comprimidas. Este comportamento é esperado para produtos de hidratação cimentícia, que se comportam mais adequadamente quando comprimidos. 
KUDLANVEC JUNIOR, V.L.; COSTA, M.R.M.M, ARGAMASSAS DE REPARO ESTRUTURAL: RESISTÊNCIA DE ADERÊNCIA SOB DIFERENTES FORMAS DE SOLICITAÇÃO. $2^{\circ}$ Simpósio Paranaense de Patologia das Construções (20 SPPC), artigo 2SPPC1001, pp. 1-13, 2017. DOI: 10.4322/2SPPC.2017.001

A resistência à tração direta resultou em $27,9 \%$ da resistência à tração na flexão em Al-1, 22,0\% em Al-2, 52,5\% em Al-3, 37,4\% em Al-4 e 41,8\% em Al-5, evidenciando que não há padrão definido para as diferentes argamassas e depende da formação das ligações de cada uma na zona de transição.

Tabela 3: Resultados dos ensaios de resistência de aderência.

\begin{tabular}{cccccc}
\hline Argamassa & \multicolumn{5}{c}{ Resistência de aderência (MPa) } \\
\cline { 2 - 6 } & $\begin{array}{c}\text { Tração } \\
\text { direta }\end{array}$ & $\begin{array}{c}\text { Tração na } \\
\text { flexão }\end{array}$ & $\begin{array}{c}\text { Cisalha- } \\
\text { mento } \\
\text { direto }\end{array}$ & $\begin{array}{c}\text { Cisalhamento } \\
\text { oblíquo }\end{array}$ & $\begin{array}{c}\text { Média da } \\
\text { argamassa }\end{array}$ \\
\hline $\mathrm{Al}-1$ & 1,38 & 4,94 & 2,01 & 6,10 & $\mathbf{3 , 6 1}$ \\
\hline $\mathrm{Al}-2$ & 1,49 & 6,76 & 2,16 & 7,38 & $\mathbf{4 , 4 5}$ \\
\hline $\mathrm{Al}-3$ & 0,74 & 1,41 & 0,92 & 1,42 & $\mathbf{1 , 1 2}$ \\
\hline $\mathrm{Al}-4$ & 1,25 & 3,34 & 1,71 & 5,38 & $\mathbf{2 , 9 2}$ \\
\hline $\mathrm{Al}-5$ & 1,23 & 2,94 & 1,26 & 3,85 & $\mathbf{2 , 3 2}$ \\
\hline $\begin{array}{c}\text { Média do } \\
\text { ensaio } \\
\text { (MPa) }\end{array}$ & $\mathbf{1 , 2 2}$ & $\mathbf{3 , 8 8}$ & $\mathbf{1 , 6 1}$ & $\mathbf{4 , 8 3}$ & $\begin{array}{c}\text { Média } \\
\text { geral 2,88 }\end{array}$ \\
\hline
\end{tabular}

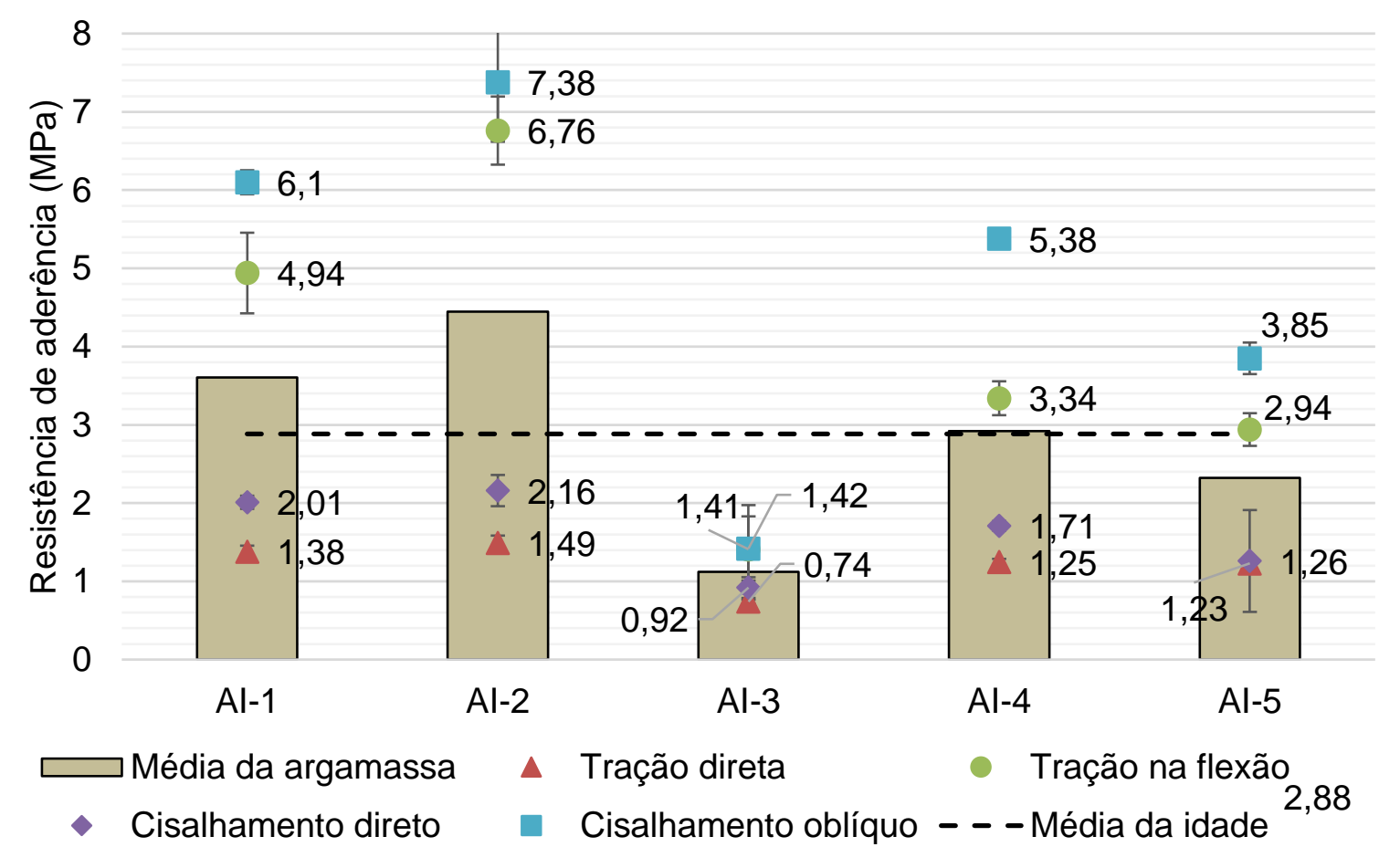

Figura 9: Resultados dos ensaios de resistência de aderência apresentados graficamente.

Com relação aos ensaios de resistência de aderência ao cisalhamento, nota-se que o comportamento ao cisalhamento oblíquo é bastante superior às outras formas de solicitação para as argamassas, com exceção de Al-3. Isto pode ser influência do plano comprimido devido à geometria do ensaio, mesmo com um ângulo de plano de 
cisalhamento consideravelmente obtuso. Este é um efeito benéfico para o reparo quando nesta situação de cargas. O cisalhamento direto apresentou, para todas as argamassas à exceção de Al-3, ruptura no substrato, como apresentado na figura 10 . Este padrão mostra que o comportamento da aderência ao cisalhamento de argamasssas de reparo é superior que a própria resistência do substrato, que teoricamente é um material mais íntegro. Isso, somado aos resultados de ruptura ao cisalhamento oblíquo, demonstra que argamassas de reparo resistem mais satisfatoriamente às tensões tangenciais do que às normais.

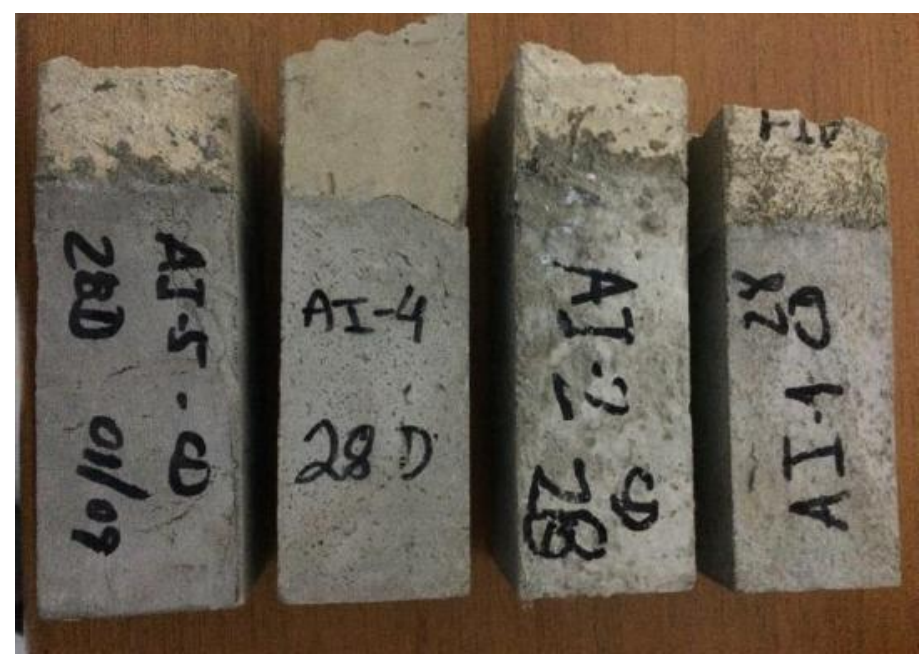

Figura 10: Padrão de ruptura dos corpos de prova ao cisalhamento direto

O teste de variância ANOVA realizado para o experimento de dois fatores (tipo de argamassa e tipo de ensaio) com confiabilidade de 95\% mostrou que há significância de resultados entre os diferentes tipos de argamassas, bem como há significância entre os tipos de ensaios, comprovando desta forma que as argamassas de reparo têm comportamentos distintos para diferentes tipos de solicitação para todas as idades ensaiadas, conforme apresentado na tabela 4.

Tabela 4: Teste de variância ANOVA.

\begin{tabular}{|c|c|c|c|c|c|}
\hline Fonte & SQ & GDL & MQ & Teste F & F Tab \\
\hline Tipo de argamassa & 655,84 & 7 & 93,7 & 625,2 & 2,2 \\
\hline Tipo de ensaio & 164,76 & 3 & 54,9 & 366,5 & 2,7 \\
\hline Interação & 501,35 & 21 & 23,9 & 159,3 & 1,7 \\
\hline \multirow[t]{2}{*}{ Dentro grupo } & 9,59 & 64 & 0,1 & & \\
\hline & 331,55 & 95 & & & \\
\hline
\end{tabular}

A figura 11 mostra que apesar das diferenças de comportamento, a correlação entre os esforços de tensões normais é forte e demonstra certo padrão. Com relação à figura 12 e a correlação entre os esforços de tensões tangenciais, apesar da ótima correlação, deve ser levado em conta que as rupturas aconteceram em locais diferentes em ambos os ensaios. 


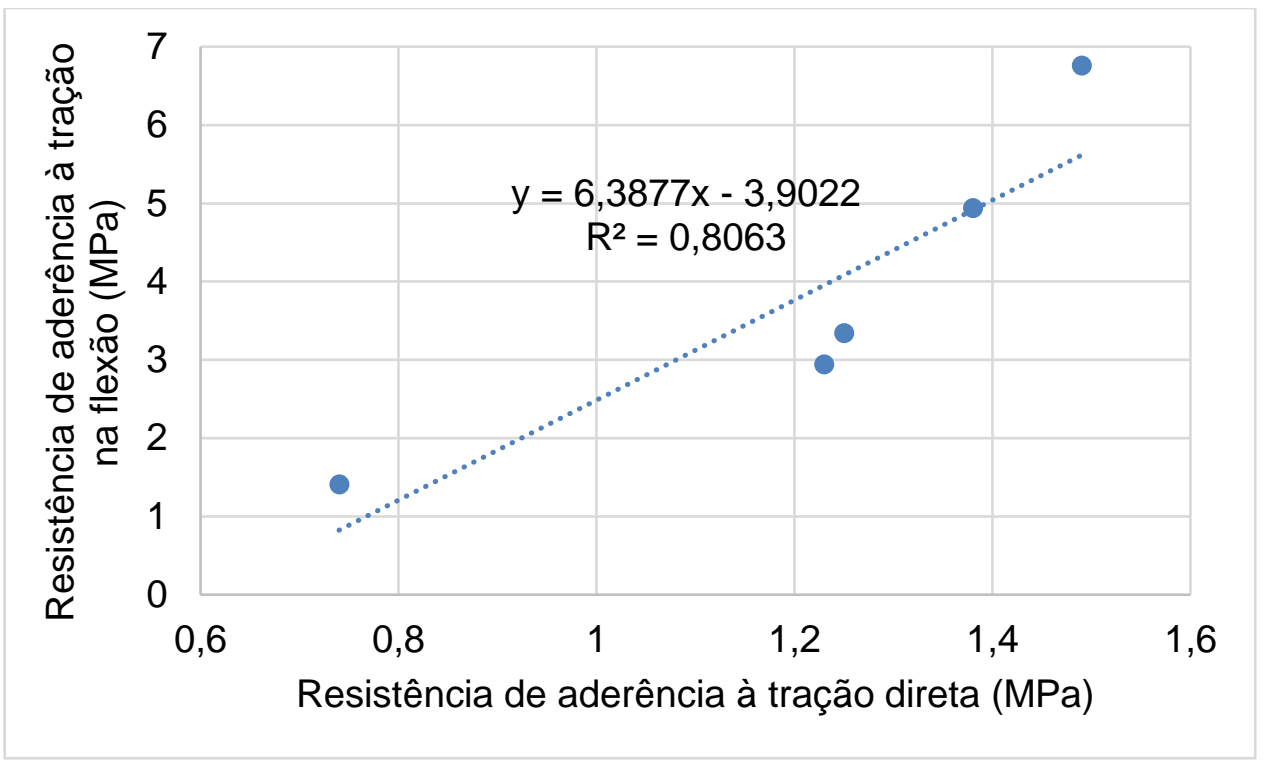

Figura 11: Correlação entre a resistência à tração direta e à tração na flexão.

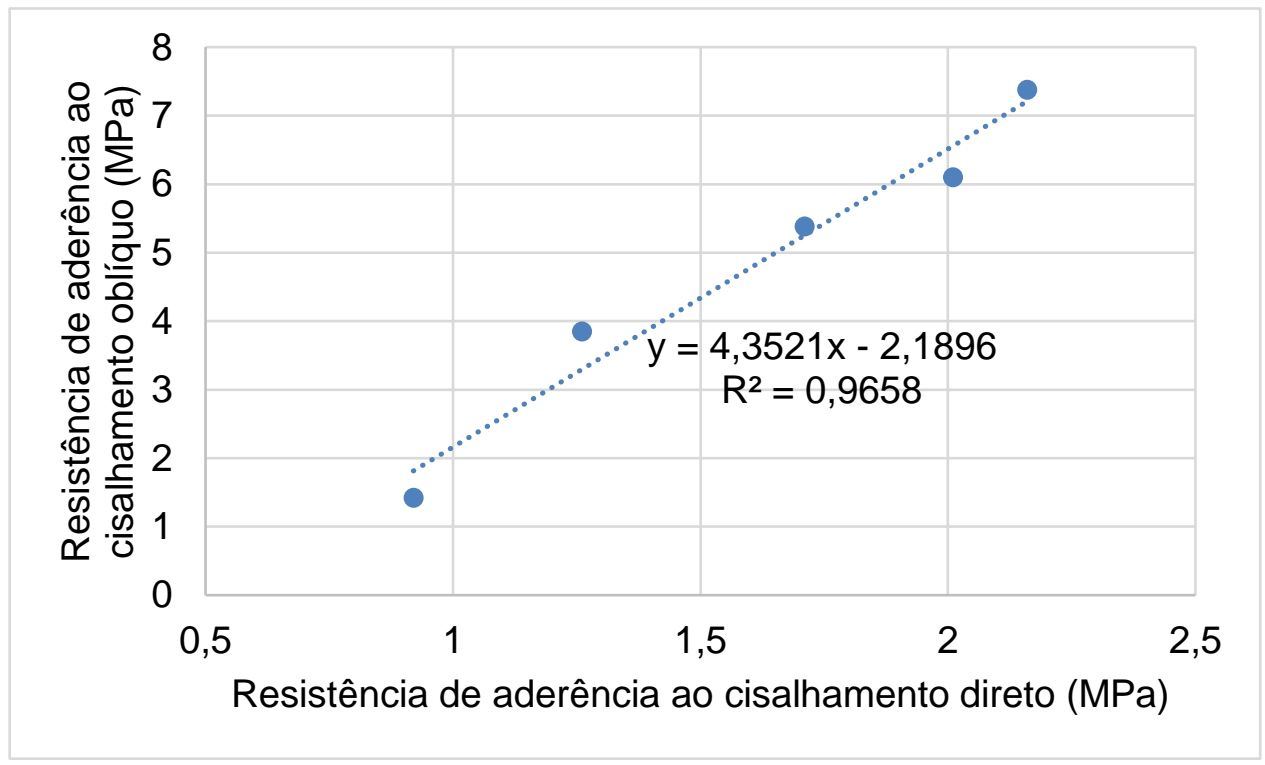

Figura 12: Correlação entre a resistência ao cisalhamento direto e ao cisalhamento oblíquo.

\section{Conclusões}

Ao final dos ensaios, conclui-se que as argamassas de reparo industrializadas têm faixas de resistência distintas, mesmo sendo classificadas como estruturais.

Mostrou-se com este trabalho o comportamento particular da resistência de aderência para cada tipo de esforço solicitante do sistema de reparo, sendo que esforços que produzam zona comprimida na seção transversal do reparo criam efeito benéfico na zona de transição, tanto para o cisalhamento, freando o deslizamento sobre o plano de cisalhamento, quanto para a tração na flexão. 
O ensaio de tração direta comprovou que o arrancamento é o elo mais frágil do sistema de reparo. A resistência a este esforço se mostra uma fração que gira entre $22 \%$ a $52,5 \%$ da resistência à tração na flexão das argamassas estudadas.

A zona de transição de sistema de reparo é mais eficiente quando solicitada ao cisalhamento, tanto oblíquo, onde resultaram as maiores resistências de aderência, quando direto, onde para quatro das cinco argamassas testadas, a zona de transição foi mais resistente que o próprio substrato. Apenas Al-3 não seguiu este padrão.

\section{Agradecimentos}

Ao Laboratório de Materiais e Estruturas da Universidade Federal do Paraná pelo espaço físico e equipamentos.

\section{Referências}

[1] Schueremans, L, Cizer, Ö, Janssens, E, Serré, G, and Van Balen, K. Characterization of repair mortars for the assessment of their compatibility in restoration projects: Research and practice. Constructions and Building Materials, 25, 12 (dez. 2011), 4338-4350.

[2] Van Balen, K., Papayianni, I., Van Hees, R., Binda, L., and Waldum, A. Introduction to requirements for and functions and properties of repair mortars. Materials and Structures, 38, 12 (Out. 2005), 781-785.

[3] Emmons, P. H. and Waysburd, A. M. System concept in design and construction of durable concrete repairs. Construction and Building Materials, 10, 1 (Jul. 1995), 69-75.

[4] Austin, S., Robins, P., and Pan, Y. Tensile bond testing of concrete repairs. Materials and Structures, 28, 5 (Jun. 1995), 249-259.

[5] Costa, E. B. C. Análise de parâmetros influentes na aderência de matrizes cimentícias. 206f. Tese (Doutorado em Engenharia Civil) - Programa de Pós Graduação em Engenharia Civil, Escola Politécnica da Universidade de São Paulo., São Paulo, 2014.

[6] Associação Brasileira de Normas Técnicas. NBR 13278 - Argamassa para assentamento de paredes e revestimento de paredes e tetos - Determinação da densidade de massa e do teor de ar incorporado. Rio de Janeiro, 2005.

[7] Associação Brasileira de Normas Técnicas. NBR 13279 - Argamassa para assentamento e revestimento de paredes e tetos - Determinação da resistência à tração na flexão e à compressão. Rio de Janeiro, 2005.

[8] Helene, P. R. L. Manual para reparo, reforço e proteção de estruturas de concreto. Pini, São Paulo, 1992.

[9] Rehabilitar, RED. Manual de reparo, proteção e reforço de estruturas de concreto. Cyted, São Paulo, 2003.

[10] Zhou, J., Ye, G., and Breugel, K. V. Cement hydration and microstructure in concrete repairs with cementitious repair materials. Construction and Building Materials, 112, 1 (Jun. 2016), 765-772. 
[11] Associação Brasileira de Normas Técnicas. NBR 13528 - Revestimento de paredes e tetos de argamassas inorgânicas - Determinação da resistência de aderência à tração. Rio de Janeiro, 2010.

[12] Alliche, A. and Mallat, A. Mechanical investigation of two fiber-reinforced repair mortars and the repaired system. Construction and Building Materials, 25, 4 (Abr. 2011), 1587-1595.

[13] Yunpeng, L., Fazhou, W., Muyu, L., and Shuguang, H. A microstructural approach to adherence mechanism of cement and asphalt mortar (CA mortar) to repair materials. Construction and Building Materials, 66, 1 (Set. 2014), 125131.

[14] Medeiros, M. H. F., Helene, P. R. L., and Selmo, S. Influence of EVA and acrylate polymers on some mechanical properties of cementitious repair mortars. Construction and Building Materials, 23, 7 (Jul. 2009), 2527-2533.

[15] Doria, M. R., Sales, A. T. C., and Andrade, N. F. A. Aderência aço-concreto e entre concretos de diferentes idades em recuperação de estruturas. Revista IBRACON de Estruturas e Materiais, 8, 5 (Out. 2015), 604-624. 